\title{
DLC Coated Ring Pack For Heavy Duty Diesel Engines
}

\author{
Rafael Antonio Bruno ${ }^{1}$, Rafael Bettini Rabello ${ }^{1}$, Davi Antonio Silva ${ }^{1}$ e Dr. Juliano Avelar \\ Araujo $^{1}$ \\ ${ }^{1}$ MAHLE Metal Leve S.A. \\ E-mails: rafael.bruno@br.mahle.com,rafael.rabello@br.mahle.com, \\ davi.silva@br.mahle.com,juliano.araujo@br.mahle.com
}

\section{SUMMARY}

Demand for improved fuel efficiency is a must for modern HDD engine developments. Direct contributions from Power Cell Unit (PCU) to reduce mechanical losses are getting close to the technical limit. Going forward improvements are focusing on liners with smoother honing and the use of low viscosity lube oils, which will play an important role in meeting this demand. Moreover, the use of pre/post treatment systems makes the life of the PCU components harder.

The focus of the new PCU development is now driven by improved robustness in order to keep the functional aspects even under harsh boundary condition. From the PCU stand point, the ring pack is the most technically challenged sub-system with regards to tribological issues, due to higher wear ratio and scuffing risk.

In order to attend to this demand, this paper proposes a novel low friction DLC (diamond-like carbon) coating for piston rings as an enabler to allow the use of low viscosity oils. The DLC coating for rings requires specific features, which differs from the use of DLC for other applications. Thickness, hardness and composition were developed specifically for HDD piston ring application.

Rig tests demonstrate outstanding scuffing resistance for DLC piston rings, even combined with very low viscosity oils. The high durability of the developed ring/liner system has been confirmed by engine tests.

\section{INTRODUCTION}

Improving efficiency is a constant target for internal combustion engines. Government legislations and society pressure are tightening the limits for green-house-gas emissions, as well as pushing for reducing the fuel consumption targets. Previously most of the efforts to reduce friction have been focused on the design of piston rings and pistons, which are the main contributors to the mechanical losses. For the piston rings, the main contributor is the Oil Control Ring (OCR) which can represents almost 70\% of the whole ring pack friction. The V-Shape OCR that allows a tangential load reduction of $50 \%$ was then developed to address this demand [1]. Nevertheless special attention is now being dedicated to reduce engine mechanical losses by reducing the oil viscosity, enabling efficiency improvements in engine technology as well as directly delivering the fuel-efficiency benefits that properly formulated lower viscosity oils can provide. 
By this factor (reduce mechanical losses) and also the attention of the manufacturers to meet the tight exhaust gas legislations, enhancing the combustion temperature, surface pressure load and high pressure fuel injection, the operating conditions of the piston rings has become more severe [2].

This dual strategy has a high impact on power cell, especially for the ring pack, once it is the most demanded sub-system with regards to tribological issues, by increasing the wear of the components and the scuffing risks.

The piston rings for Heavy Duty Diesel (HDD) application typically receive a coating on their outer diameter surface. This coating is designed to improve the wear resistance, withstand scuffing demand and reduce friction.

Thus, a novel DLC coating was engineered to not only provide a low friction coefficient and suitable durability, but also to work as an enabler for the use of lower viscosity oils on HDD applications. Then the aim of this paper is to present an innovative ring pack which combines excellent friction properties and offering full life durability for highly loaded HDD engines.

\section{LOW VISCOSITY OILS ON HDD ENGINES}

The use of low viscosity oils is an effective way to reduce fuel consumption in internal combustion engines. One of the parameters most accepted as a standard in the industry is the High-temperature, High-shear (HTHS) dynamic viscosity. This is a measure of the temporary viscosity loss of oil under high shear at elevated temperatures and the number equates to the resistance to flow of the oil. The lower the HTHS value, the higher the potential is for helping improve the fuel economy.

In HDD applications, the most common specified oils have a minimum HTHS viscosity rate of 3.5mPa.s [3]. Several engine manufacturers have proposed a reduction of the oil viscosity to $2.9 \mathrm{mPa}$.s and $2.6 \mathrm{mPa}$.s for future engines creating a challenging opportunity for components development. One solution is the application of hydrogen free carbon coated piston ring pack to assure engine durability.

\subsection{Ring Pack Design Features}

The following design changes are typically seen on modern engine platforms to reduce ring pack Friction Mean Effective Pressure (FMEP) [4, 5]:

- Ring pack tension reduction.

- Ring axial width reduction.

- Use of wear resistant O.D. coatings or treatments with small coefficients of friction under boundary and mixed lubrication conditions.

- Use of optimized ring profiles to enhance hydrodynamic lubrication with the cylinder bores.

It is important to point out that these changes should be combined with changes to the surrounding components, in order to provide an optimum system. If only the ring pack is optimized there is a risk of jeopardizing some system performance, therefore optimization should be done in a combined and structured way. 
The interactions between the components of the system require the implementation of a suitable methodology for the development of low friction ring packs. Combining investigation techniques and tools, environment understanding, and component expertise is essential.

It is important to differentiate characteristics like cylinder pressure, bore distortion and temperature (defined by the OEM's base engine design during the early stage of engine development) from those such as bore tribology and piston deformation (part of the PCU system). The latter allows for component design synergies for optimization of low friction technologies while maintaining acceptable oil transport in the PCU.

The lubrication function of the ring pack is to supply the required amount of oil to critical surface interfaces, namely the liner and the piston groove. A minimum liner oil film thickness is required to allow hydrodynamic lubrication and is therefore important for friction and wear

Oil is also needed in the first piston groove to lubricate the ring and groove contact surfaces to avoid excessive wear. High temperatures limit the residence time of oil in the top ring groove and increase the risk of carbon deposits and ring sticking. Lubrication "refreshment" should be done with a continuous oil supply to the groove. This quantity should be limited and controlled in order to avoid oil loss and therefore excessive oil consumption. Optimization of the entire PCU system must be done by controlling oil supply and release in each region of influence to achieve efficient lubrication while minimizing friction power losses and oil consumption.

The chart below (Figure 1) summarizes the typical ring pack design for a modern HDD application.

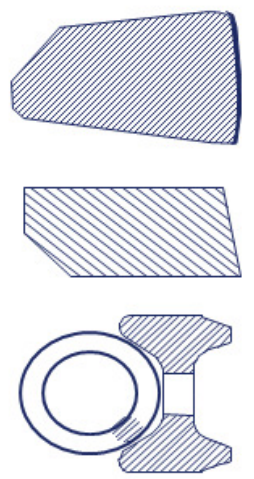

2.5 to $3.5 \mathrm{~mm}$ made of steel. Coating with high wear resistance to maintain optimum barrel shape (hydrodynamic) and fine cylinder honing. Coating with low coefficient of friction. Protection on the lower flank

2.0 to $2.5 \mathrm{~mm}$ taper ring of martensitic cast iron or steel. OD coating or surface treatment for wear resistance (poor quality fuel, high fuel dilution)

$2.5 \mathrm{~mm}$ to $3.5 \mathrm{~mm}$ oil ring with low tension tolerance, low land/rail widths with high wear resistance coating to maintain it over the engine lifetime and low coefficient of friction

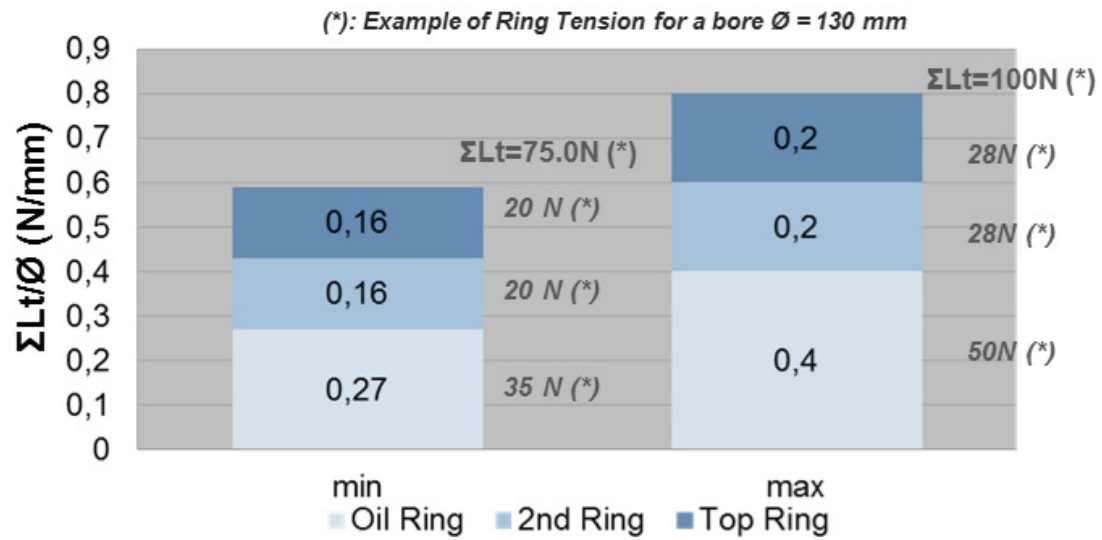

Figure 1: Ring pack outline for modern HDD applications. 


\subsection{State of art for piston rings coating}

Galvanic coatings have historically played a big role in the HDD scenario, mainly due to the durability, low cost and level of scuff resistance required in older engines. Due to these aspects, the galvanic coatings still present big market share for the HDD application field, however environmental constraints and the need for higher scuff resistance will be a hurdle for future applications for this category of coating.

Ceramic coatings like the chromium nitride $(\mathrm{CrN})$ coating are technologically relevant since the 1980's [4]. Their use in internal combustion engines has been motivated mainly due to the high hardness along with low coefficient of friction [5].

For almost a decade, $\mathrm{CrN}$ coatings were the focus of research and its properties were improved by working with the coating morphology, introducing $\mathrm{CrN}$ based multilayer structures and improving chemical stability to offer the adequate stability for use in internal combustion engines.

CrN coatings are currently selected for modern HDD engines with high combustion pressures and reduced lubrication oil availability, where additional toughness and wear resistance are required from piston rings. Typical coating thickness is $30 \mu \mathrm{m}$ for this kind of application.

Furthermore the productive process of Physical Vapor Deposition (PVD) for such CrN coatings is more environmentally friendly than galvanic coatings in terms of the by-products of the application process.

\subsection{DLC coating for piston rings}

A wide variety of amorphous carbon based materials are classified as DLC (Figure 2), consequently the right choice of coating system is the key to obtain the best balance between low friction and durability. For example, piston rings are subjected to high thermal and mechanical loads and, more recently, scuffing risk increased by reduction of the oil viscosity, where thin oil films can bring more contact between the rings and the liners. 


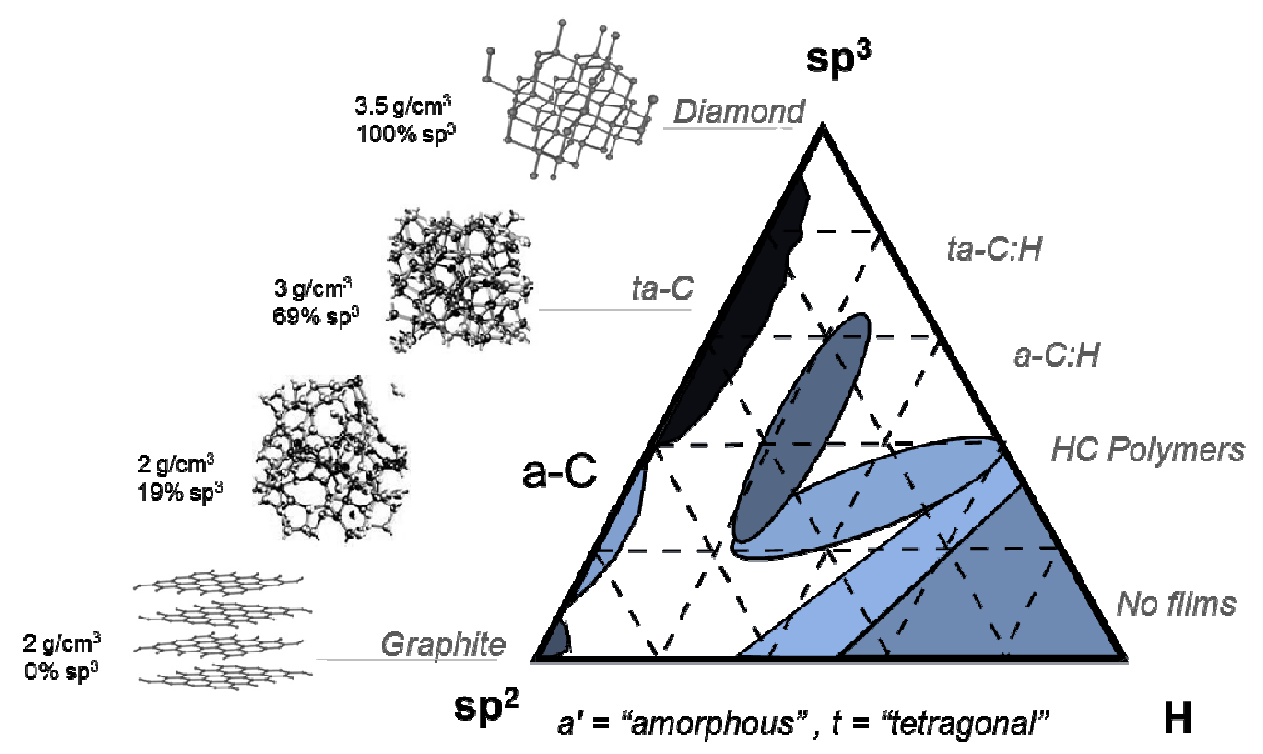

Figure 2: Different DLC coatings and their classification.

The concept is to have the balance between the amount of sp3 and sp2 connections and the lowest content of hydrogen in order to bring the DLC properties in line with the demands of HDD engines. Thus it is necessary for sound adhesion, whether on upper compression rings or on oil control rings, and a thickness that will guarantee a whole life coating. Additionally a bond layer is added to improve adherence of the DLC layer.

Bench tests and engine tests have already demonstrated superior wear resistance and lower coefficient of friction compared to current ceramic coatings, such as Chromium Nitride coatings applied by PVD, thus manufacturers are already evaluating this coating for future HDD developments.

Another important parameter on piston rings with DLC coating is the surface roughness that has a direct impact on friction and system wear (Figure 3a). One of the wear mechanisms in piston rings occurs in the boundary lubrication (Figure 3b), when ring and liner surface slide each other causing elevated localized pressure between the asperities in contact, resulting in a plastic deformation, breaking the roughness peaks and consequently removing material (adhesive wear). The top piston rings are especially submitted to the boundary lubrication regime, whilst the oil control rings operate typically more time in the mixed and fluid-film regimes. Nevertheless, with the introduction of low HTHS oils, there is a tendency of increasing the piston rings operating time in the boundary lubrication.

Thus the minimum roughness peaks in the DLC coating is important to allow the minimum asperities contact in the boundary and mixed regimes, improving the coefficient of friction and the system wear. 
a).

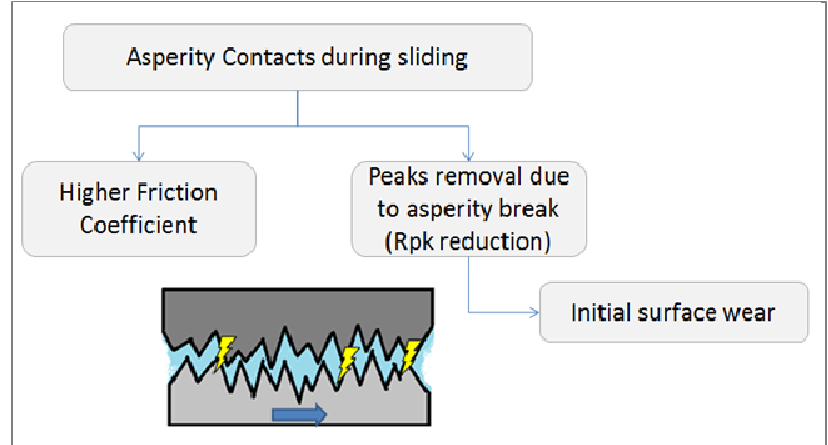

b).

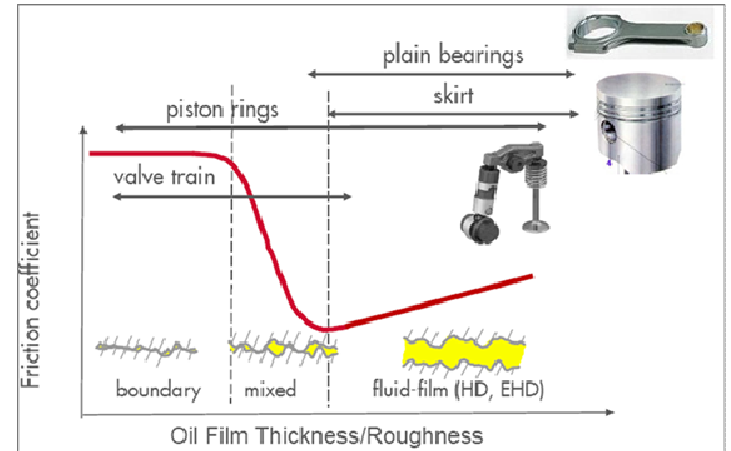

Figure 3: a) Asperity contacts during sliding and b) operating lubrication regimes of piston rings.

This makes it necessary to develop a new surface finishing process on such a hard coating aiming to reduce the surface roughness inherent from the DLC deposition process.

The scanning electron microscope (SEM) analysis with 1500x magnification shows the coating surface in the as plated condition (Figure 4a) and after the coating surface finishing (Figure $4 \mathrm{~b}$ ). The secondary electrons (SE) signals, which are emitted by atoms near the surface of the sample material being more surface sensitive, were used to evaluate the surface topography of the coating.

In the as plated condition, it can be observed a rough structure with high number of peaks, which may jeopardize the friction coefficient and the system wear as explained above. Then, the after finishing image illustrates a defined plateau formation aspect with a high contact area (peaks were removed) with some small valleys that serve as oil reservoir. The main challenge in transforming this surface is the necessity of development of new processes and abrasives for finishing the high hardness hydrogen free carbon coatings.
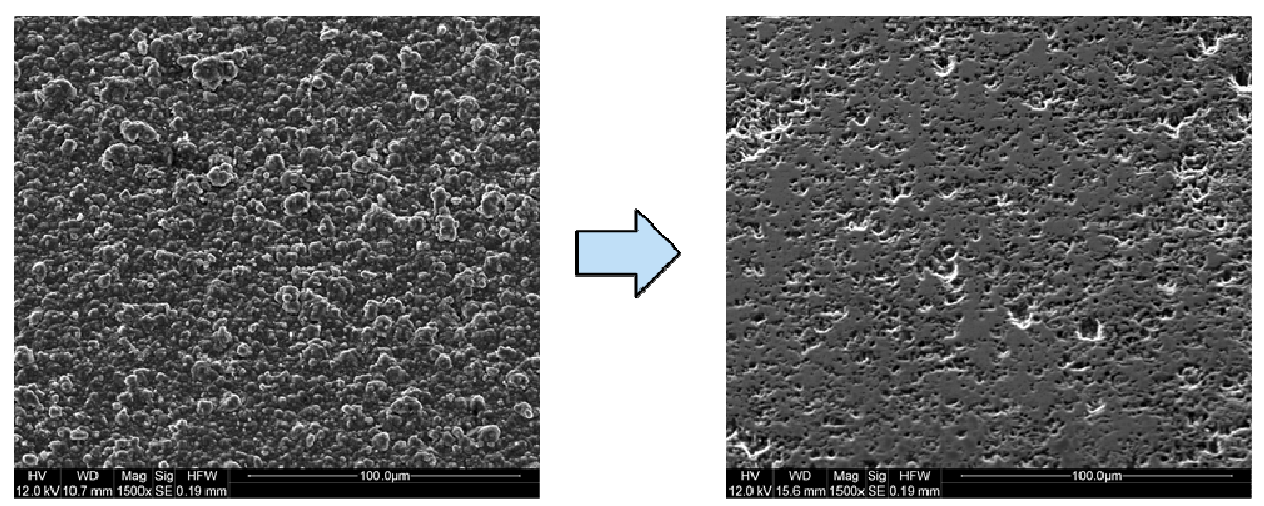

Figure 4: SEM image of the a) DLC surface as plated and b) DLC surface after finishing. 


\section{RIG BENCH TEST RESULTS}

\subsection{Scuffing resistance and friction bench test}

The protocol for scuffing evaluation on rig test was adapted from the work of Wolfle et al. [6,7]. Basically, a short ramp scuffing test using the SRV (Schwing Reib Verschleiss) reciprocating tester was developed by MAHLE to allow the test to be performed with actual ring and liner parts and to use fully formulated oil with temperatures and loads similar to the engine operation conditions.

It consists of a reciprocating rig test with load, frequency, angle and temperature control, as well as friction coefficient measurements through a pair of load cells. Oil injection is controlled with a high precision pump.

An investigation of the scuffing resistance, represented by the scuffing load ( $\mathrm{ScL}$ ) in the vertical axis of Figure 5, using two different oils formulations, was performed with the typical automotive piston rings coating CrN-based PVD and the hydrogen free carbon coatings (MAHLE H-free DLC) developed for the low HTHS viscosity oils application.

The graph shows that the hydrogen free carbon coating has the highest scuffing resistance, with a scuffing load (ScL) higher or equal than $1000 \mathrm{~N}$ (maximum equipment limit) using both low viscosity oils (HTHS $2.9 \mathrm{mPa}$.s and HTHS $2.6 \mathrm{mPa} . \mathrm{s}$ ), whilst the $\mathrm{CrN}$ coatings presented scuffing loads varying from 550 to $800 \mathrm{~N}$ and 350 to $550 \mathrm{~N}$ depending on the oil viscosity. Visual post-test analysis also showed no signs of scuffing on MAHLE H-free DLC or their liner counterparts.

It can be concluded that MAHLE carbon based coating shows a superior scuffing resistance and compatibility with low HTHS oils, becoming an enabler for $\mathrm{CO}_{2}$ reduction (even with low viscosity oil formulations).

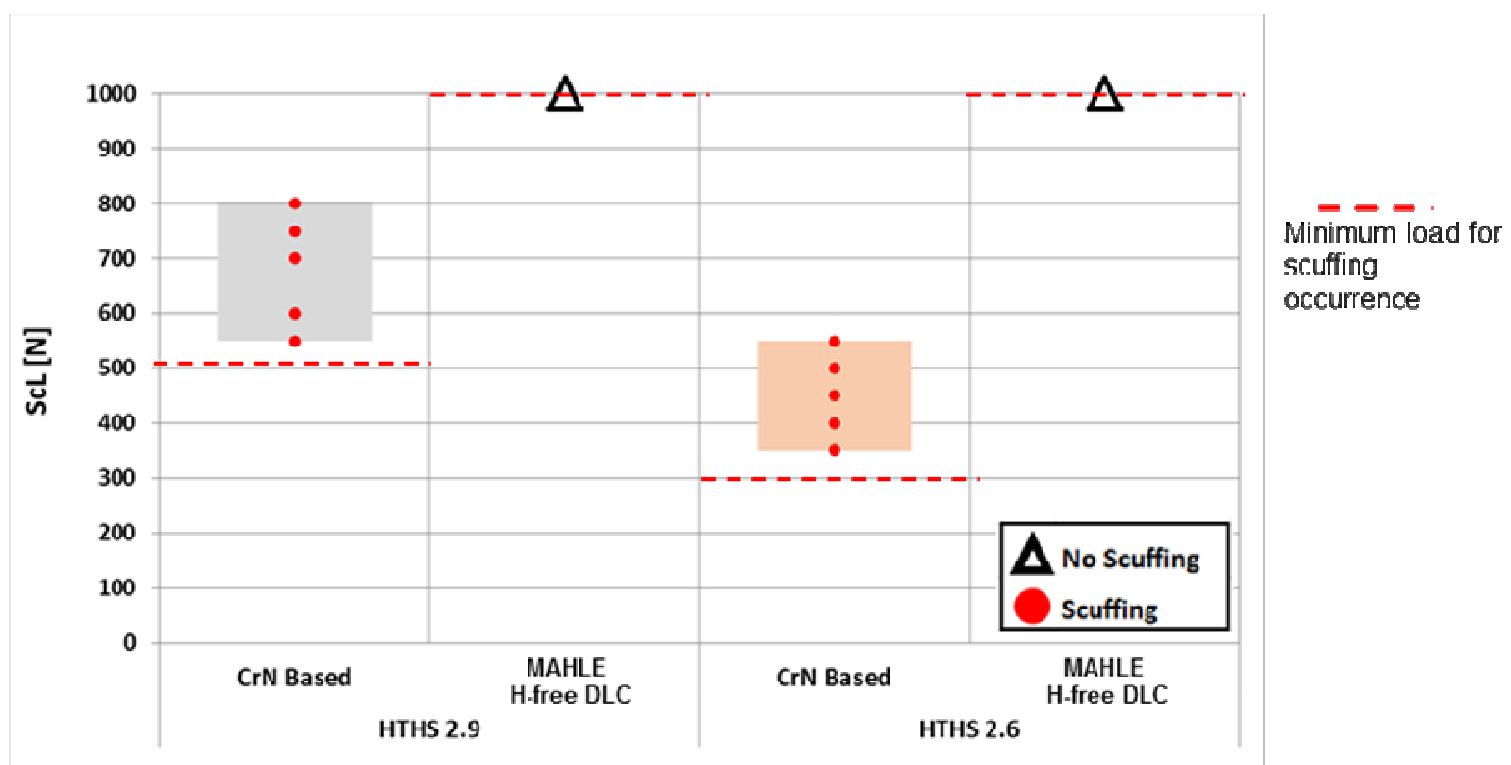

Figure 5: Scuffing load results for CrN-based PVD coating and MAHLE H-free DLC under different HTHS oils [11]. 
During the scuffing resistance test, the coefficient of friction $(\mathrm{CoF})$ was monitored and the friction curve is illustrated in the Figure 6. The MAHLE H-free DLC coating shows a CoF of less than 0.10 and keeps this value over the whole test. The $\mathrm{CrN}$-based coating showed a $\mathrm{CoF}$ of less than 0.15 during the first thirty minutes of test. After that, it can be observed some instabilities and a sudden increase with 50 minutes characterized by the scuffing occurrence. The visual analysis of the CrN-based coating pieces after the test confirmed the scuffing occurrence (strong scratches), whilst the MAHLE H-free DLC pieces are presenting typical ring and liner contact pattern after the scuffing resistance test. While in the ring, a uniform and homogenous contact is observed, in the liner it can be still identified the honing responsible for the oil flow along the cylinder.



Figure 6: CoF during scuffing test and visual analysis after test [11].

\subsection{Wear resistance rig bench test}

Besides the high scuffing resistance and low CoF of the DLC coating, it is important also to preserve wear resistance that will define the durability of the component. Relative ring coating wear was evaluated in a reciprocating bench test. The experimental setup is shown in Figure $7 \mathrm{a}$, where a normal load is applied using a closed-loop servo mechanism, and normal load and friction forces are measured with strain-gages. . The test consists of a ring running against a cylinder liner with an applied nominal pressure of $12 \mathrm{MPa}(120 \mathrm{bar})$ and a rotational speed of $900 \mathrm{rpm}$ for 4 hours. To accelerate ring wear, the oil is doped with hard alumina particles. Ring wear is measured by comparing the respective profile, before and after test (Figure 7b). The tribological condition on the rig test is based on a predominance of boundary behavior emphasizing the coating properties. 
a).



b).

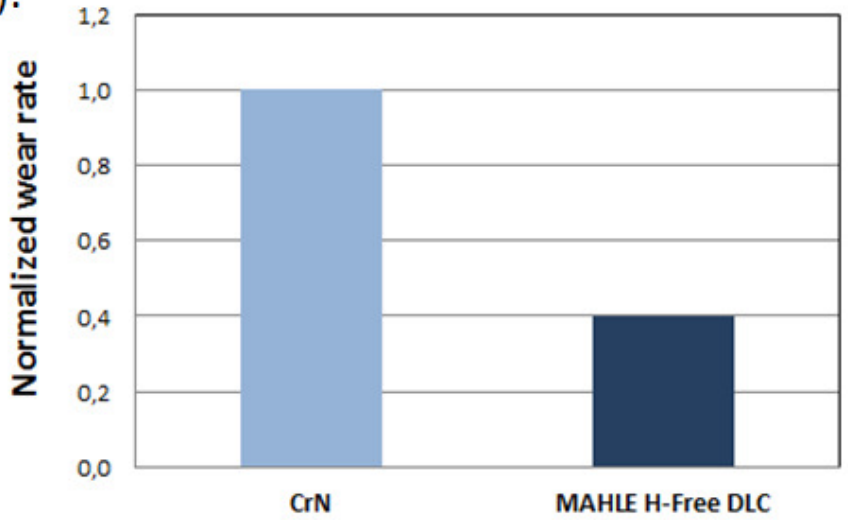

Figure 7: Ring coating wear in a reciprocating bench test. (a) Sketch of reciprocating procedure; (b) wear results [8].

Figure $7 \mathrm{~b}$ shows that the wear resistance of MAHLE H-free coating is more than double of the wear resistance of CrN-based PVD coating. The novel carbon based MAHLE concept applied by PVD process was also found to show higher wear resistance than the Ceramic coating available for this sort of applications (piston ring).

\section{ENGINE DYNO TEST RESULTS}

To evaluate the DLC rings under engine test conditions, a pool of tests were performed in order to check wear resistance, coating stability in working conditions and compatibility with the power cell system. The main test results are explored below.

\subsection{DLC vs. Galvanic Coating Top Ring Test}

DLC coated rings were evaluated in a 1000h Thermo-shock Durability Test HDD engine platform with $29 \mathrm{~kW} / \mathrm{L}$ and $\mathrm{PCP}=23.0 \mathrm{MPa}$ using $2.9 \mathrm{HTHS}$ oil. For this evaluation a split test configuration was performed on top ring with DLC rings and a galvanic coated design that represents a significant part of the market segment.

DLC ring visual aspect after 1000h showed in general, good aspect for tested parts without chipping, spalling or scoring, as seen on Figure 8. Distribution of contact pattern (lighter gray color) is also inconspicuous with minimal contact at peripheral running face area and increased contact at ring gaps.



Figure 8: Overall top ring condition after Test. DLC coated rings on positions \#1, \#3 and \#5 and Galvanic rings in the positions \#2, \#4 and \#6. 
Figure 9 brings detailed view of both galvanic and DLC rings tips region, which is the most wear demanding region of the ring. The visual aspect of the parts start to illustrate differences between the ring coating variants tested, with the DLC coating presenting reduced contact width condition, while the galvanic coating design, presented a larger contact width as an indication of higher wear and signs of burning marks, an indicative of early stage of adhesive wear / scuffing.

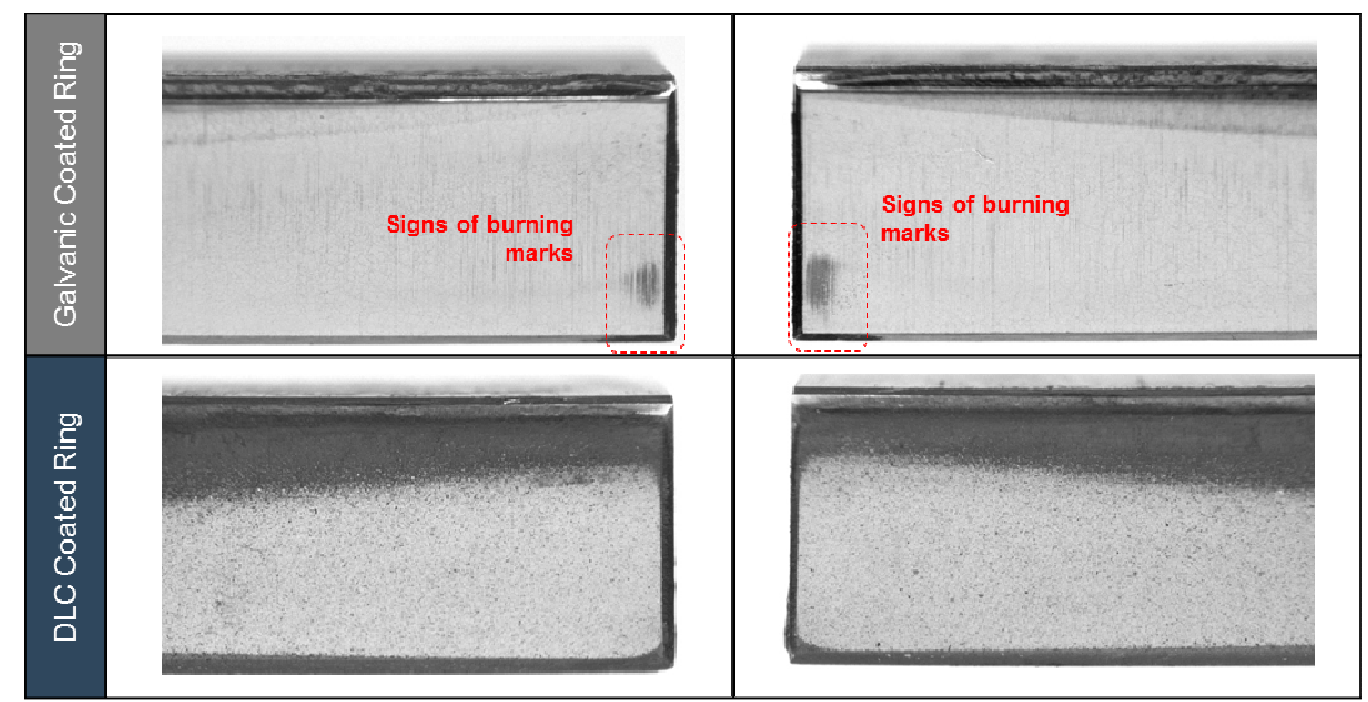

Figure 9: Representative ring tip condition of tested variants showing lower ring contact width in the DLC coated ring and absence of burning mark.

The radial wear was obtained by the overlap of the ring profile before and after the engine test. Figure 10 then illustrates the higher wear resistance of the DLC coating in comparison to the galvanic coating both at the tips and non tips.

At least $40 \%$ of wear reduction in average was achieved, attributed to the better tribological properties and high hardness of the hydrogen free carbon coatings. These results are fundamental to design the necessary coating thickness for the complete engine lifetime.

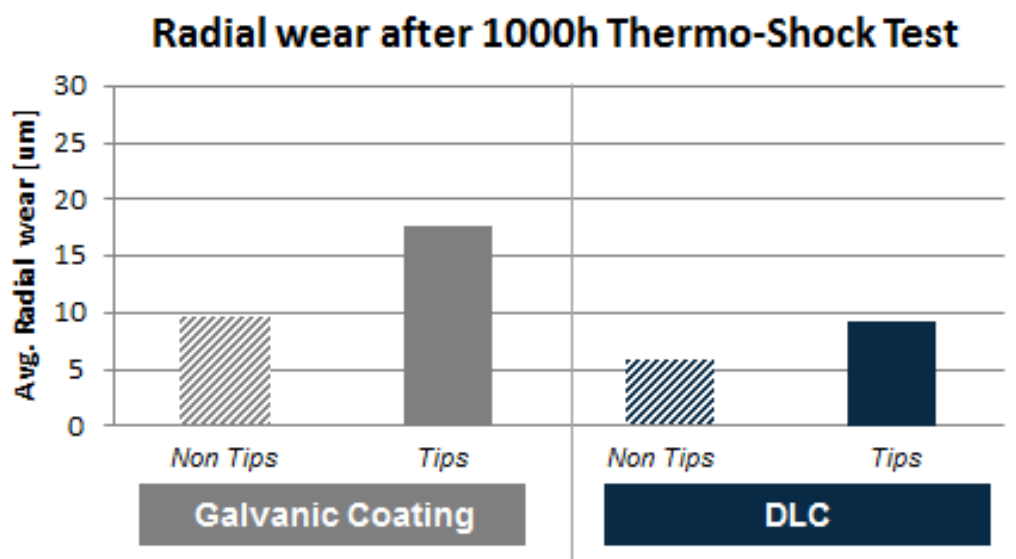

Figure 10: Radial wear analysis of tested ring variants.

Regarding the interaction between rings and cylinder liners, an equipment that scans the cylinder liner inner surface was used to compare besides the visual aspect, as scratches and 
scuffing marks, the amount of polished areas (absence of honing) mainly identified in the top dead center. Figure 11 compares typical images of cylinder liners that ran with galvanic coating top piston rings and DLC top piston rings. In both cylinders, no scratches or scuffing marks were identified and similar polished area can be seen in the top dead center. This means that the DLC coated piston rings brings minor impact to the cylinder liner surface.
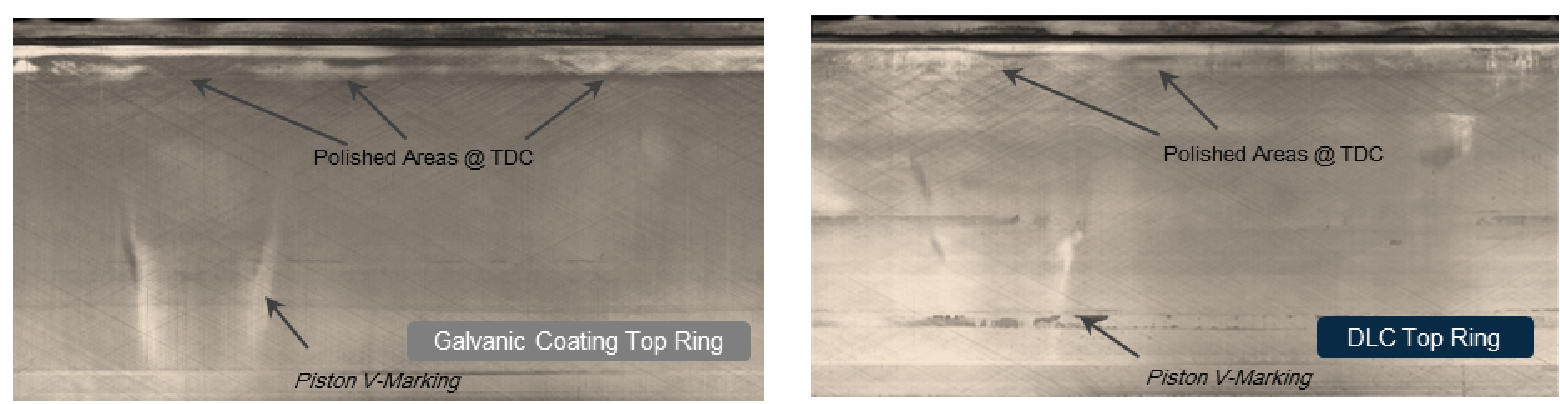

Figure 11: Plain view of cylinder liner with characterization of visual aspect after test.

The cylinder liner wear was also evaluated by profile measurements in the top dead center and is showed in the Figure 12, as an average of all measurements. Although the DLC coated top ring presents a slight higher wear on the liners in comparison to the galvanic coating piston rings, the total wear of 5um does not impact the liner performance even after $1000 \mathrm{~h}$ engine test.

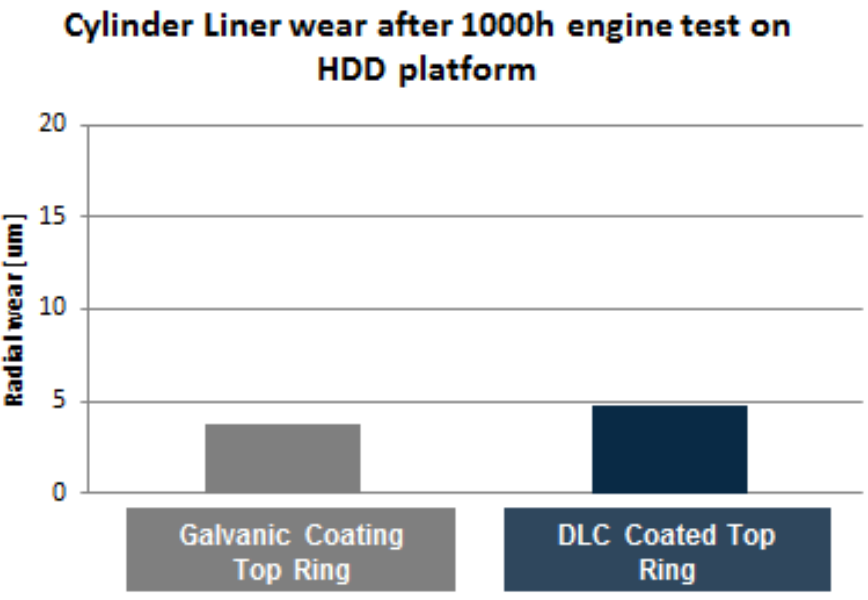

Figure 12: Avg. Cylinder liner wear after $1000 \mathrm{~h}$ testing time.

\subsection{DLC vs. CrN PVD vs. Oil viscosity change (top ring test)}

Detailed study of the impact of reducing oil viscosity was carried out in order to investigate their effects over PCU components [11]. In this study comparison of current solutions like CrN PVD and future technologies like DLC were evaluated in engine test conditions.

Figure 13 shows a comparison of the top ring visual aspect after $500 \mathrm{~h}$ accumulated testing time. The CrN PVD coated top ring was tested with HTHS 3.7 oil and HTHS 2.9mPa.s oil. For the HTHS 2.9 oil, 3 cylinders were assembled with DLC coated top ring and the remaining positions with PVD rings. 
Both top ring variants presented good visual aspects without burning mark and coating spalling, however, with clear contact face increase for the CrN PVD tested with low viscosity oil grade. This is an indication of higher ring coating wear as the oil viscosity is decreased. The DLC coated piston ring, even running with the HTHS 2.9mPa.s oil, still presents a running face contact lower or at least in similar level than CrN PVD test with HTHS 3.7mPa.s oil.
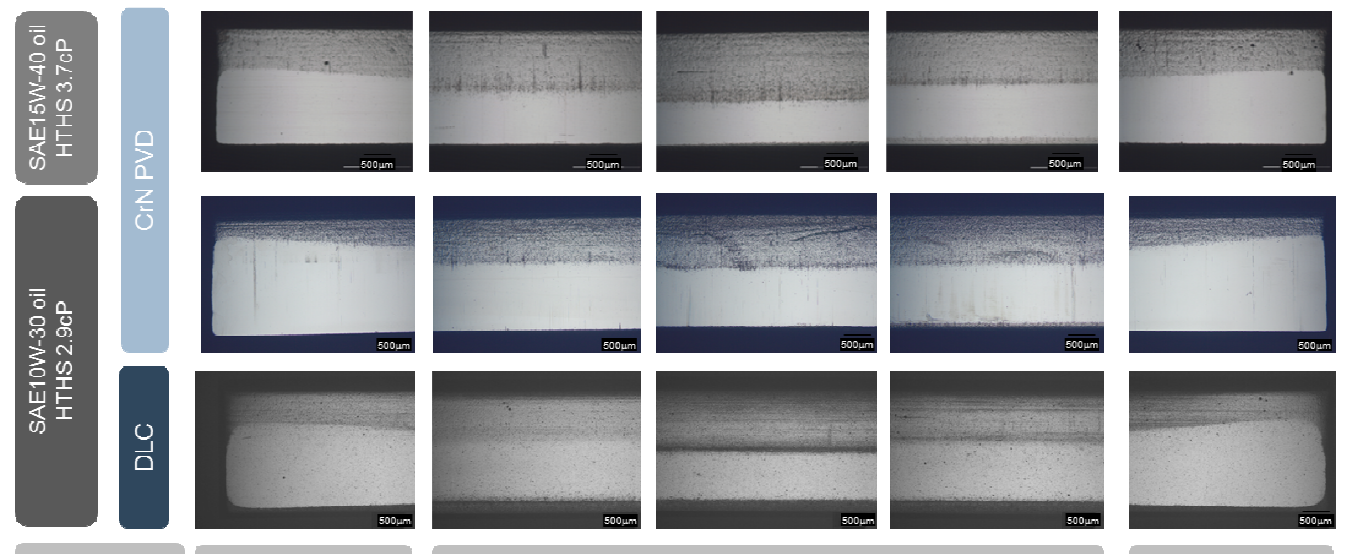

Figure 13: Visual aspects of top ring sets after 500h HDD engine tests.

A more detailed investigation of the face wear, Figure 14, demonstrates the impact of the oil on CrN PVD top rings, with a wear increase of $18 \%$ avg. when switching from HTHS3.7 to 2.9 oil. The DLC coating offered a wear reduction of $44 \%$ compared to $\mathrm{CrN}$ in the same 2.9 HTHS oil.

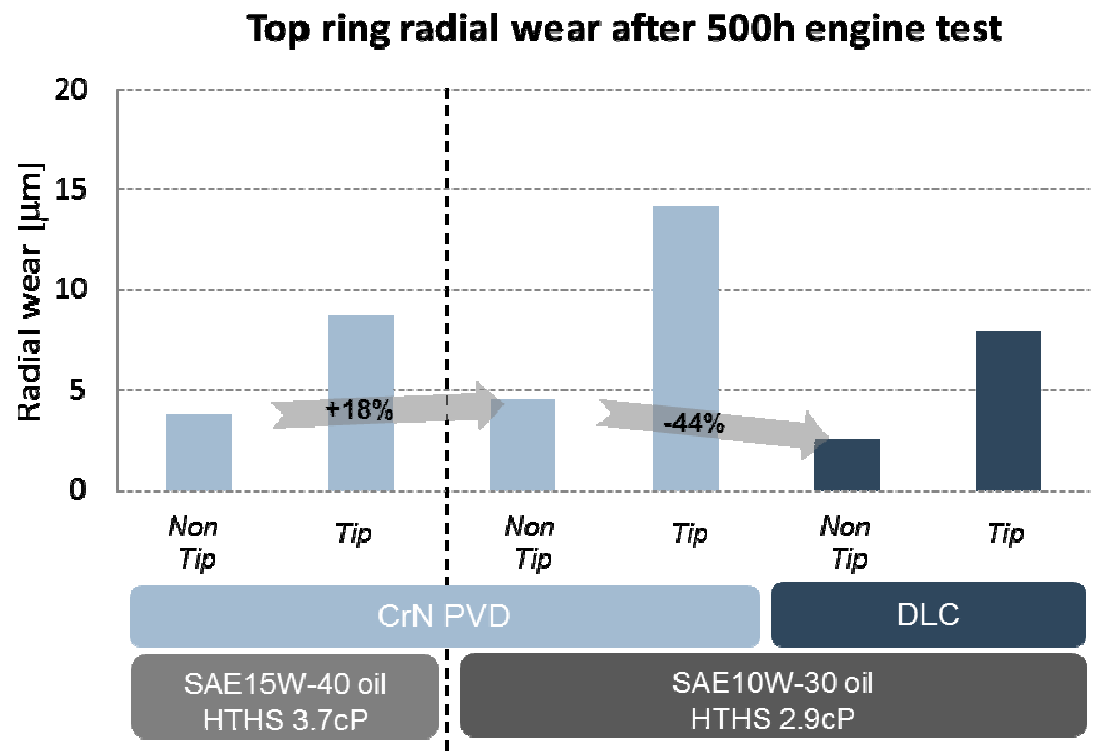

Figure 14: Radial wear of top ring after 500h engine tests.

\subsection{DLC ring pack test}

DLC coated top ring and oil control ring were evaluated in a 1000h Thermo-Shock Durability test HDD engine platform with 30kW/L and PCP=23.0 MPa, using HTHS 2.9mPa.s oil. 
Top ring visual aspect after 1000h showed excellent aspect for tested parts without chipping, coating spalling or scoring. Distribution of contact pattern is also inconspicuous with minimal contact on the peripheral running face area and slight contact increase at ring tips (Figure 15).



Tips

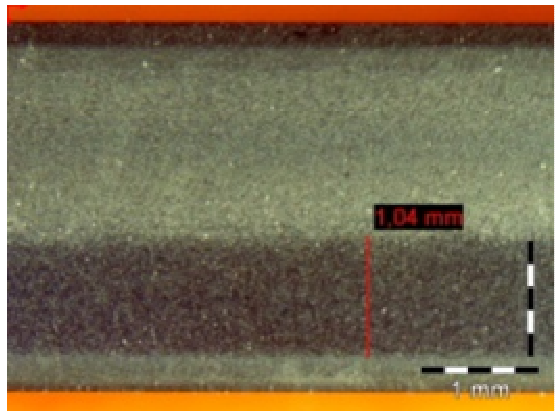

Non Tips

Figure 15: Representative aspect of DLC coated top ring after test.

DLC coated top rings concluded test with outstanding wear performance with less than $3 \mu \mathrm{m}$ of wear at non tips regions and only $7 \mu \mathrm{m}$ of wear on average at ring tips (Figure 16).



Figure 16: Top ring Radial wear after 1000h test.

Similar to the results of the top rings, the oil ring visual aspect after $1000 \mathrm{~h}$ showed in general, good aspect for parts after test, without chipping, coating spalling or scoring (Figure 17)

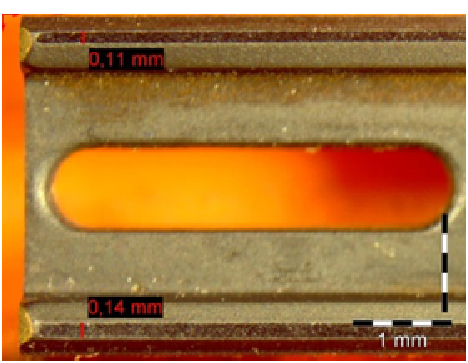

Tips

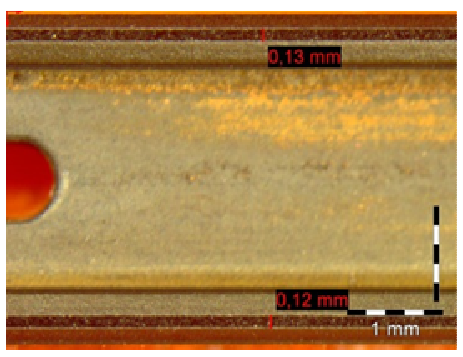

Non Tips

Figure 17: Representative aspect of DLC coated oil ring after test. 
The contact pattern was homogeneous and uniform along whole ring peripheral surface and ring profile is also well preserved due to the low wear verified on tested parts. Figure 18 shows a wear lower than 3 um in average after $1000 \mathrm{~h}$ thermo-shock test.

As a consequence of the low wear rates presented by the DLC coated oil rings, the unitary pressure loss of the oil rings were also reduced, resulting in only $7 \%$ reduction after $1000 \mathrm{~h}$ of testing time.


Figure 18: Oil Ring Radial Wear and Unitary Pressure Loss after 1000h engine test.

\section{CONCLUSION}

A novel hydrogen free carbon piston ring coating was successfully developed for both top and oil control rings. This coating combines the best properties of ceramic coatings applied by PVD (excellent wear resistance, thermal and chemical stability, robust production process) with the major benefits of DLC like coatings (low coefficient of friction and excellent scuffing resistance).

The higher scuffing resistance than ceramic coatings was demonstrated by the rig bench tests. The scuffing load (ScL) for the DLC coating achieved the maximum equipment load and presented a very low initial and final coefficient of friction.

The excellent wear resistance was also proven in rig and engine bench tests. The DLC coated piston rings had a considerably lower wear when tests with low HTHS oils were performed. Furthermore, it has been demonstrated to be a robust coating for the whole engine lifetime against scratches and scoring marks, without jeopardize the cylinder liner performance.

Thus the DLC coated ring pack is recommended for future applications with low HTHS oils, aiming friction reduction with robustness in terms of wear and scuffing resistance. 


\section{REFERENCES}

[1] Bieneman, J., Bruno, R., Nocera, E., Silva, D. "High Durability and Low Fuel Consumption Ring Pack for HDD Engine”, SAE World Congress 2013, 2013-01-1725.

[2] Cucu1, A. C. "New coatings and finishing methods for top piston rings of Diesel engines to reduce frictional loss and to ensure adequate behavior under most difficult regimes of operation”, 8th International Conference on Material Science \& Engineering, BRAMAT, 2013.

[3] Engine Technology International.com, March 2017.

Available at https://commercial.lubrizoladditives360.com/wp-content/uploads/2017/04/1761861-EN-LZA-Engine-Technology-International-March2017291.pdf.

Accessed on: 31/05/2017.

[4] Ehnis, H., Deuß, T., Freier, R. "Friction Mapping -Reibleistungsmessungen am befeuerten Vollmotor" In: Tagungshandbuch, 11 $^{\text {th }}$ symposium Dieselmotorentechnik, Technische Akademie, Esslingen, 2008.

[5] Ferrarese, A.; Tomanik, E. "Low Friction Ring Pack for Gasoline Engines", ASME ICEF2006-1566, Sacramento, USA, 2004.

[6] Rejowski, E., Tomanik, E, Souza, J. P. "Low viscosity oils impact on Heavy Duty Diesel engine components", p. 118-130 . In: Anais do XXIV Simpósio Internacional de Engenharia Automotiva - SIMEA 2016, São Paulo, 2016. ISSN 2357-7592, DOI 10.5151.

[7] Aubert A., Gillet R., Gaucher A., Terrat J.P. "Hard chrome coatings deposited by physical vapour deposition. Thin Solid Films. 1983;108(2):165-172.

[8] Mayrhofer P.H., Willmann H., Mitterer C. "Oxidation kinetics of sputtered $\mathrm{Cr}-\mathrm{N}$ hard coatings". Surface and Coatings Technology. 2001;146-147:222-228.

[9] Obert, P., Müller, T., Füßer, H.; Bartel, D. “ The influence of oil supply and cylinder liner temperature on friction, wear and scuffing behavior of piston ring cylinder liner contacts - a new model test". In: Tribology international. - Amsterdam [u.a.]. Elsevier Science, Bd. 94.2016, S. 306-314

[10] Wölfle, P., Goergen, F., Füßer, H., Bartel, D. "Einfluss des Prüfprogramms auf die ertragbare Belastung des Reibkontaktes Kolbenring gegen Zylinderlaufbahn im SRVTribomete"r. In: Reibung, Schmierung und Verschleiß ; Bd. 2. - Aachen : GfT; 2015, S. $66 / 1-66 / 12$

[11] López, D., Huegel, R, Nocera, E, Araujo, Juliano, Nascimento, L. "Innovative carbon coating concepts for piston rings", VDI Conference, 2016. 